www.jmscr.igmpublication.org

Index Copernicus Value: 79.54

ISSN (e)-2347-176x ISSN (p) 2455-0450

crossref DOI: https://dx.doi.org/10.18535/jmscr/v7i4.148

\title{
A Study of Evaluation of Hearing Loss in Tympanic Membrane Perforation and Hearing Outcome after Tympanoplasty
}

\author{
Dr V.P. Narve ${ }^{1}$, Dr Vinay Gangwani ${ }^{* *}$, Dr Varsha Tripathi ${ }^{3}$, Dr Deepak Parmar ${ }^{4}$ \\ ${ }^{1}$ Professor, Department of ENT Jaya Arogya Hospital, Gwalior \\ ${ }^{2,3,4}$ Post Graduate Student, Department of ENT Jaya Arogya Hospital, Gwalior \\ *Corresponding Author \\ Dr Vinay Gangwani \\ Post Graduate Student, Department of ENT Jaya Arogya Hospital, Gwalior, India
}

\begin{abstract}
Aims and Objective: Assessment of effect of size, site, location of perforation on the degree of hearing loss. To evaluate improvement in hearing after tympanoplasty.

Methodology: This is the retrospective and prospective study of 100 patients that underwent tympanoplasty at tertiary care hospital between January 2106 to June 2018. The follow up period was 1 year.

Results: Most common type of perforation was medium type of perforation with incidence of 44\%. Hearing loss was found to be maximum with large central perforation (49.7 $\pm 7.07 \mathrm{~dB})$. Mean improvement gain after tympanoplasty was also maximum with large central perforation (15.67 dB).

Conclusion: The larger the size of perforation, the larger is the hearing loss. The location of perforation has significant effect on the degree of hearing loss with posterior quadrant perforations causing more hearing loss. Tympanoplasty is a beneficial procedure for hearing improvement and eradication of disease and there is significant improvement after tympanoplasty.
\end{abstract}

\section{Introduction}

Tympanic membrane is a membranous partition separating the external auditory meatus from the tympanic cavity, measuring $9-10 \mathrm{~mm}$ vertically and $8-9 \mathrm{~mm}$ horizontally ${ }^{1}$. It plays a major role in middle ear transformer mechanism. Tympanic membrane perforation is caused by variety of causes, the most common being trauma and infections. Trauma (Barotrauma, temporal bone fracture), Infections (Acute otitis media, chronic otitis media, TB), Iatrogenic (ventilation tubes). Tympanic membrane perforation leads to varying degree of conductive hearing loss. So it is important to diagnose and treat tympanic membrane perforation as early as possible as untreated tympanic membrane perforation leads to ongoing destructive changes in the middle ear, thus adding to further hearing loss.

Chronic otitis media is a long standing infection of the middle ear cleft characterized by persistent or recurrent aural discharge, deafness and perforation of tympanic membrane.COM often results in partial or total loss of the tympanic membrane (TM) and ossicles, leading to conductive hearing loss that can range in severity up to $60 \mathrm{~dB}$. Incidence of COM is higher in developing countries like INDIA due to overcrowding, inadequate health facilities, poor hygiene, low socio-economic status, recurrent respiratory tract infections, poor nutrition \& 
pollution. Chronic otitis media can be managed in two ways, conservative and surgical management. The aim of middle ear surgery for hearing is reduction in the patient's hearing disability, not just closure of the airbone gap ${ }^{2}$. Small perforations usually heal spontaneously but when the edges of the perforation are covered by stratified squamous epithelium, a perforation becomes permanent and does not heal spontaneously ${ }^{3}$.

Among the various causes of ear diseases, COM is a major global cause of hearing impairment and may have serious long term effects on language, auditory, cognitive development and educational progress. As per $\mathrm{WHO}$, the prevalence of COM in Indian population is approximately $2 \%$ which is comparatively higher than that found in developed countries like that of USA and UK where the prevalence is $<1 \%{ }^{4}$. Majority of patients with COM do well with antimicrobial therapy but despite this there is a subset of the patients who develop serious intratemporal and intracranial complications from this otherwise self-limiting disease; and the mortality rate of these remains substantial ranging from $10-31 \%$. The diagnosis of COM needs to be made earlier in order to prevent its long-term effects especially on hearing impairment

Several therapeutic practices and regimens have evolved to treat COM, but the surgical management -tympanoplasty- has remained the ultimate choice ${ }^{5,6}$. Procedures such as grafting the tympanic membrane, alone, or in combination with ossiculoplasty (tympanoplasty with ossicular chain reconstruction), comprise the varying subtypes of tympanoplasty ${ }^{7,8}$. Type- 1 tympanoplasty is performed when there is tympanic membrane perforation without any ossicular damage ${ }^{9}$. Tympanoplasty type 1 can be nearly as straightforward as myringoplasty and for instance simply involve removal of a retracted membrane in the tympanic cavity or removal of adhesions around the ossicles but it can also be an extensive and time consuming procedure when combined with mastoidectomy procedures ${ }^{10}$. This study deals with evaluation of hearing loss in tympanic membrane perforation and functional outcome in a series of patients who underwent tympanoplasty using temporalis fascia graft/grafts from other sites.

\section{Materials \& Methods}

The study entitled to "A Study of Evaluation of Hearing Loss in Tympanic Membrane Perforation and Hearing Outcome after Tympanoplasty" conducted in the department of otorhinolaryngology \& head and neck surgery, Jayarogya group of hospitals and gajra raja medical college Gwalior (M.P.) for a period of 1 and half year from January 2017 to June 2018 and the retrospective data was collected from January 2016 to December 2016. A total of 100 cases presenting with complaints of ear discharge, impaired hearing, ear pain in the ENT ward or opd were taken for study.

Study Design: retrospective and prospective study.

\section{Inclusion Criteria}

- Cases with safe CSOM.

- Patients with age between 10 years to 50 years.

\section{Exclusion Criteria}

- Patients younger than age 10 are excluded to eliminate the possibility of inaccuracies of audiological testing in children.

- Patients older than 50 years of age were excluded because of the increased incidence of presbyacusis in this age group.

- Patients with active discharge.

- Traumatic perforation.

- Post ventilation tube insertion.

- Mixed hearing loss.

- Patients with presbycusis.

- Patients with history of familial hearing loss.

- Patients with history of prolonged exposure to noise and ototoxic drugs.

- Patients with history of head trauma.

- Patients not giving consent for the relevant investigation will be excluded from this study. 


\section{Results}

\section{1) Age distribution of patients}

In our study maximum number of patients were from age group 20-40 years (53\%), followed by $10-20$ years (41\%).

Table no. 1 : Age distribution of patients

\begin{tabular}{|l|c|c|}
\hline $\begin{array}{l}\text { Age group (in } \\
\text { years) }\end{array}$ & $\begin{array}{c}\text { Number of } \\
\text { patients }\end{array}$ & Percentage \\
\hline 0 to 20 years & 41 & $41 \%$ \\
\hline 20 to 40 years & 53 & $53 \%$ \\
\hline 40 to 60 years & 06 & $06 \%$ \\
\hline$>60$ years & 00 & $0 \%$ \\
\hline
\end{tabular}

\section{2) Sex ratio of the patients}

The total number of male and female patients in our study were 38 and 62 respectively.

Table no. 2: Sex ratio of the patients

\begin{tabular}{|l|c|c|}
\hline Sex & $\begin{array}{c}\text { Number of } \\
\text { patients }\end{array}$ & Percentage \\
\hline Male & 38 & $38 \%$ \\
\hline Female & 62 & $62 \%$ \\
\hline Total & 100 & $100 \%$ \\
\hline
\end{tabular}

\section{3) Duration of ear discharge}

The duration of ear discharge range from 3 months to 20 years with $30 \%$ of patients having ear discharge for 16 years to 20 years.

Table no. 3: Duration of ear discharge

\begin{tabular}{|l|c|c|}
\hline $\begin{array}{l}\text { Duration of } \\
\text { ear discharge }\end{array}$ & $\begin{array}{c}\text { Number of } \\
\text { patients }\end{array}$ & Percentage \\
\hline$<2$ years & 23 & $23 \%$ \\
\hline 3 to 5 years & 18 & $18 \%$ \\
\hline 6 to 10 years & 22 & $22 \%$ \\
\hline 11 to 15 years & 07 & $07 \%$ \\
\hline 16 to 20 years & 30 & $30 \%$ \\
\hline Total & 100 & $100 \%$ \\
\hline
\end{tabular}

\section{4) Duration of impaired hearing}

The duration of impaired hearing ranges from 2 months to 20 years with $44 \%$ having hearing impairement for less than 2 years.

Table no. 4: Duration of impaired hearing.

\begin{tabular}{|l|c|c|}
\hline $\begin{array}{l}\text { Duration of } \\
\text { impaired hearing }\end{array}$ & $\begin{array}{c}\text { Number of } \\
\text { patients }\end{array}$ & Percentage \\
\hline$<2$ years & 44 & $44 \%$ \\
\hline 3 to 5 years & 30 & $30 \%$ \\
\hline 6 to 10 years & 13 & $13 \%$ \\
\hline 11 to 15 years & 02 & $02 \%$ \\
\hline 16 to 20 years & 11 & $11 \%$ \\
\hline Total & 100 & $100 \%$ \\
\hline
\end{tabular}

5) Unilateral versus bilateral disease

Patients with unilateral disease were 53\% and with bilateral ear disease were $47 \%$.

Table no. 5: Unilateral v/s bilateral disease

\begin{tabular}{|l|c|c|}
\hline Ear disease & Number of patients & Percentage \\
\hline Unilateral & 53 & $53 \%$ \\
\hline Bilateral & 47 & $47 \%$ \\
\hline
\end{tabular}

6) Types of perforation

In our study most common type of perforation encountered was medium central perforation being about $44 \%$, followed by large central perforation $(37 \%)$ and small central perforation (19\%).

Table no. 6: Types of perforation

\begin{tabular}{|l|c|c|}
\hline Perforation & Number of patients & Percentage \\
\hline Small central & 19 & $19 \%$ \\
\hline Medium central & 44 & $44 \%$ \\
\hline Large central & 37 & $37 \%$ \\
\hline
\end{tabular}

7) Hearing loss associated with size of peroration

Pre-operatively hearing loss was found to be maximum with the large central perforation i.e. $49.7 \mathrm{~dB} \pm 7.07 \mathrm{~dB}$ followed by medium central perforation and small central perforation respectively.

Table no. 7: Hearing loss a/w type of perforation

\begin{tabular}{|l|c|c|}
\hline Perforation & $\begin{array}{c}\text { Number } \\
\text { of } \\
\text { patients }\end{array}$ & $\begin{array}{c}\text { Average hearing } \\
\text { loss in dB with } \\
\text { standard deviation }\end{array}$ \\
\hline Small central & 19 & $37.34 \pm 8.21$ \\
\hline Medium central & 44 & $43.98 \pm 10.40$ \\
\hline Large central & 37 & $49.7 \pm 7.07$ \\
\hline
\end{tabular}

8) Hearing loss associated with duration of ear discharge

More the duration of discharge is, more is the hearing loss.

Table no. 8: Hearing loss $\mathrm{a} / \mathrm{w}$ duration of ear discharge

\begin{tabular}{|l|c|c|}
\hline $\begin{array}{l}\text { Duration of ear } \\
\text { discharge }\end{array}$ & $\begin{array}{c}\text { Number of } \\
\text { patients }\end{array}$ & $\begin{array}{c}\text { Average hearing loss } \\
\text { in dB with standard } \\
\text { deviation }\end{array}$ \\
\hline Less than 2 years & 44 & $37.64 \pm 6.35$ \\
\hline 3 to 5 years & 30 & $46.22 \pm 10.70$ \\
\hline 6 to 10 years & 13 & $46.98 \pm 10.69$ \\
\hline 11 to 15 years & 02 & $47.6 \pm 9.76$ \\
\hline 16 to 20 years & 11 & $45.2 \pm 12.55$ \\
\hline
\end{tabular}




\section{9) Post operative outcome}

Outcome following tympanoplasty was measured in terms of Post-operative Audiometry done 4-6 months after surgery, which showed significant improvement in average hearing thresholds. Mean improvement gain of observed in patients operated for large central perforation, medium central perforation, small central perforation are $15.67 \mathrm{~dB}, \quad 12.75 \mathrm{~dB}$, and $\quad 7.39 \mathrm{~dB}$ respectively with individual $\mathrm{p}$ value $=0.00$.

Table no. 9 : Post-operative outcome

\begin{tabular}{|l|c|c|c|c|}
\hline Type of perforation & $\begin{array}{c}\text { Pre operative PTA } \\
\text { with standard } \\
\text { deviation }\end{array}$ & $\begin{array}{c}\text { Post operative PTA } \\
\text { with standard } \\
\text { deviation }\end{array}$ & $\begin{array}{c}\text { Mean gain in } \\
\text { dB }\end{array}$ & $\begin{array}{c}\text { P } \\
\text { value }\end{array}$ \\
\hline Small central perforation & $37.34 \pm 8.21$ & $29.95 \pm 7.32$ & 7.39 & 0.00 \\
\hline Medium central perforation & $43.98 \pm 10.40$ & $31.23 \pm 8.75$ & 12.75 & 0.00 \\
\hline Large central perforation & $49.7 \pm 7.07$ & $34.03 \pm 7.74$ & 15.67 & 0.00 \\
\hline
\end{tabular}

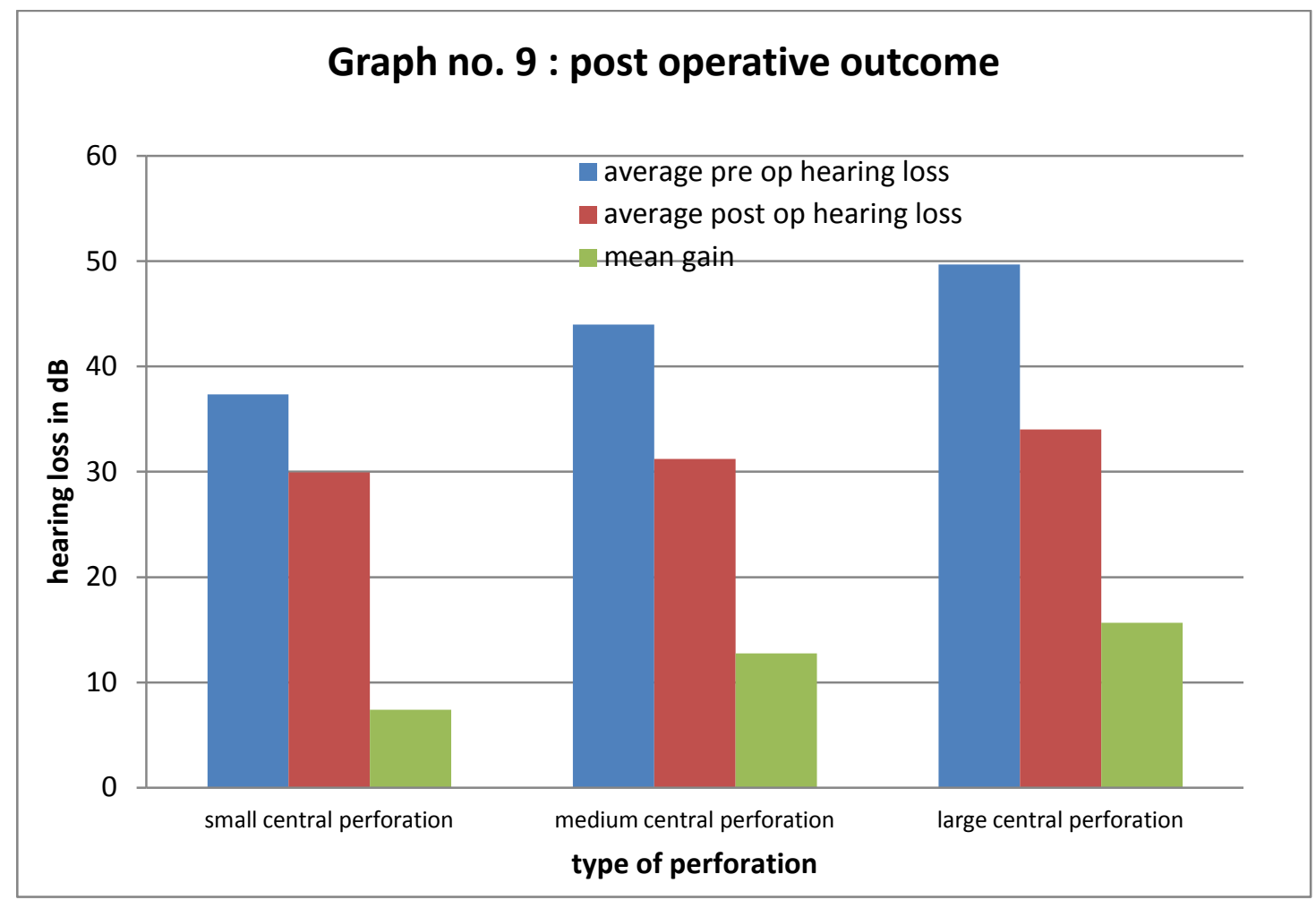

\section{Discussion}

$\mathrm{COM}$ is one of the commonest conditions, which the Otorhinolaryngologists encounter in day to day practice. The tubotympanic type of COM usually presents with perforation of tympanic membrane with normal ossicular chain. The delicate ossicle with poor blood supply is more susceptible to be eroded by the middle ear disease like COM both in atticoantral as well as tubotympanic type as reported by various authors and in our study too.

Sakagami $M$ et al observed that chronic otitis media as the main cause of hearing loss, in which
82 out of 91 cases were with chronic otitis media had an tympanic membrane perforation with intact ossicular chain. Therefore the main cause of hearing loss was tympanic membrane perforation and not the other ossicular pathology.

100 patients of tubotympanic type of COM were included in our study. Maximum numbers of patients $53 \%$ were found in the age group of 20 to 40 years. Rout et $a l^{11}$ in their study observed that maximum number of patients 64 cases were in the age group of 20-30 years. Varshney et $a l^{12}$ observed that the most commonly affected age group was between 16-25 years. 
In our study, the male to female ratio was 1:1.63. In the conducted by Kashyap et $a l^{13}$, out of the 100 patients 30 were males and 70 were females.

The duration of ear discharge ranged from 2 months to 20 years, with 30 cases having duration in the range of 16-20 years.

The duration of hearing loss ranges from 2 months to 20 years, with 44 cases having duration less than 2 years. The duration of hearing loss was in all cases found to be lesser the duration of ear discharge. This may be attributable to difficulty in appreciating minor degrees of hearing loss by the patient. The hearing loss would be noticed only when the disease has progressed sufficiently to cause a significant impairment of hearing by perforation or ossicular destruction. Similar findings were observed in the study conducted by Sakagami $M$ et al, Varshney et al ${ }^{12}$

Unilateral disease was observed in 53 cases and bilateral disease was seen in 47 cases.

The most common type of perforation encountered in our study was medium central perforation in $44 \%$ of cases followed by large central perforation in $37 \%$ of cases. Sharma et al ${ }^{14}$ observed the most common type of perforation was central with an incidence of $69.77 \%$. Kamal et $a l^{15}$ found an incidence of central perforation in COM of $93 \%$ in their study population of 203.

In our study, the average hearing loss was found to be maximum with large perforation that is 49.7 $\pm 7.07 \mathrm{~dB}$, followed by medium central perforation that is $43.98 \pm 10.40 \mathrm{~dB}$. Studies conducted by Teja D.D. et $a l^{16}$,Gudepu et $a l^{17}$, Walter $P$ et al, Vose SE et al, Ahmed SW et al, Ibekwe TS et al, Oluwole $M$ et al, Mehta RP et al showed that with increasing size of perforation hearing loss increases.

In our study mean improvement gain of observed in patients operated for large central perforation, medium central perforation, small central perforation are $15.67 \mathrm{~dB}, 12.75 \mathrm{~dB}$, and $7.39 \mathrm{~dB}$ respectively with individual $\mathrm{p}$ value $=0.00$.

Mean hearing improvement of $8.0 \mathrm{~dB}$ was observed in 281 cases of tympanoplasty in a study conducted by Palva and Ramsay et $a l^{18}$ in 1995.
In a study conducted by Lee et $a l^{15}$ in $2002 ; 261$ cases of tympanoplasties were followed up and their mean improvement hearing gain was observed to be $8.1 \mathrm{~dB}$.

In a study conducted by Batni $\mathrm{G}$ and Goyal $\mathrm{R}$ et al in $2014^{48}, 88$ out of 100 patients had intact and completely healed grafts at 1 year postoperatively (success rate of $88 \%$ ). The Hearing gain achieved was $14.55 \mathrm{~dB}$ and the mean air bone gap reduction was $11.94 \mathrm{~dB}$. This reduction was statistically significant when compared to the pre-operative hearing conditions.

\section{Conclusion}

$\mathrm{COM}$ is a well-known disease presenting with ear discharge and hearing loss. Hearing loss can occur because of perforation as well as with ossicular pathology.

In most cases, ossicular pathologies are late to occur if perforation are not timely care off and treated.

The larger the perforation, greater is the hearing loss in decibels. Large central perforations involving all the 4 quadrants results in more degree of hearing loss.

Duration of ear discharge also have significant effect on the magnitude of hearing loss, the longer the duration of ear discharge the greater is the hearing loss.

Tympanoplasty is a beneficial procedure for hearing improvement and the eradication of the disease. It provide a dry ear and improvement in hearing. Mean improvement gain in hearing observed in patients operated for large central perforation, medium central perforation and small central perforations are $15.67 \mathrm{~dB}, 12.75 \mathrm{~dB}, 7.39$ $\mathrm{dB}$ respectively. Socially, adequate hearing has been obtained in a significant percentage of cases and the results are comparable to those of other authors.

\section{References}

1. Donaldson JA, Duckert LG. Anatomy of the ear. In: Paparella MM, Shumrick DA, editors. Otolaryngology.Basic sciences and 
related principles.3. Philadelhia: WB Saunders Company : 1991.

2. Browning GG et al Scott-brown's otorhinolaryngology head and neck surgery, 7th edn. 3:3421.

3. Khan NA. Repair of traumatic perforation of tympanic membranes by a new technique. Pak J Otolaryngol. 1992;8:177179.

4. Adkins WY. Composite autograft for Tympanoplasty \& tympanomastoid surgery. Laryngoscope. 1990;100:244-7.

5. Committee on conservation of hearing of the American Academy of Ophthalmology and Otolaryngology. Standard classification for surgery of chronic ear disease.Arch Otolaryngol. 1965;81:204-5.

6. Austin DF. Ossicular reconstruction.Arch Otolaryngol. 1971;94:525-35.

7. Javed M, Khan S, Ullah H, Shah J. Onlay versus underlay myringoplasty, audiological results. Pak J Otolaryngol. 2000;16:59-60.

8. Vrabec JT, Deskin RW, Grady JJ. Metaanalysis of pediatric tympanoplasty. Arch Otolaryngol.1999;125(5):530-534. doi: 10.1001/archotol.125.5.530.

9. Ashfaq M, Aasim MU, Khan N. Myringoplasty: anatomical and functional results. Pak Armed Forces Med J. 2004;54

10. Meyer AG, Albers FW et al (1997) Validation of hearing results in tympanoplasty. In: Huettenbrink (ed) Middle ear mechanics in researches and otosurgery.

11. Rout MR, Des P, Mohanty D, Rao V, Susritha K, Jyothi BE. Ossicular chain defects in safe type of chronic suppurative otitis media. Indian J Otol 2014;20:102-5.

12. Varshney S, Nangia A, Bist SS, Singh RK, Gupta N, Bhagat S. Ossicular chain status in chronic suppurative otitis media in adults. Indian J Otolaryngol Head Neck Surg 2010;62:621.
13. Kashyap SK, Bhoopendra Singh, Purohit JP, Ajay Pratap Singh, MohdAzeem; Incidence of ossicular chain pathology in Tubotympanic CSOM. J of Evaluation of medical and Dental Sci, 2015; 4(67): 11701-7.

14. Sharma M, Shetty D.P. Ossicular status in patients operated for chronic suppurative otitis media. Int J Res Rev 2016;4(9):16101616.doi:10.17511/ijmrr. 2016.i09.16.

15. Kamal N, Joarder AH, Chowdhary AA, Khan AW. Prevalance of chronic suppurative otitis media among the children living in two selected slums of Dhaka City.Bangladesh Med Res Counc Bull. 2004 Dec;30(3):95-104

16. Teja D D, Rhea P. Influence of Tympanic Membrane Perforation on Hearing Loss. Glob J Oto 2017; 5(5): 555673. DOI: 10.19080/ GJO.2017.05.555673.

17. Gudepu P, Kesavan B, Kanchumurthy A. Comparative study of hearing loss with site and size of perforation. J. Evid. Based Med. Healthc. 2016;3(41),2035-2040.DOI: $10.18410 / \mathrm{jebmh} / 2016 / 454$.

18. Palva T, Ramsay H. Myringoplasty and Tympanoplasty results related to training and experience. Clinical Otolaryngology and Allied Sciences. 1995; 20:329-35. 